\title{
Geçmişten Günümüze Cerrahi ve Cerrahi Hemşireliğinin Yeri
}

\author{
Dilek AYGİN*, Aysel GÜL**
}

\begin{abstract}
$\ddot{\mathbf{O z}}$
İnsanoğlunun en büyük arzusu, uzun bir yaşam ve ölümsüzlük olmuştur. Bu amacı gerçekleştirme çabası içerisinde olan insan, yaşam mücadelesinde pek çok travma ve yaralanmalara maruz kalmıştır. Ortaya çıkan bu tablo, cerrahinin gelişimine hız kazandırmıştır. Yapılan incelemeler cerrahi uygulamaların, hastalı̆̆ tedavi etmek, hasarı onarmak ve iyileştirmek gibi nedenlerin yanı sıra büyücülük gibi birtakım dini amaçlara hizmet etme amacıyla da kullanıldığını ortaya koymaktadır. Geçmişten günümüze cerrahinin tanılanması ve kullanılan yöntemlere ilişkin topluluklar arasında belirgin farklılıklar olduğu belirtilmektedir. Geçmişte trepenasyon (kafatasını delme), drenaj, yara tedavisi vb. gibi daha basit birtakım uygulamalarla başlayan cerrahi, günümüzde bilim ve teknolojide yaşanan hızlı gelişmelerle birlikte yerini robotik cerrahi, transluminal endoskopik cerrahi vb. gibi birtakım yöntemlere bırakmıştır. Bilim ve teknolojideki öngörülemez bu hızlı değişimlerin cerrahiyi/cerrahi hemşireliğini ne boyutta etkileyeceğini kestirmek ise oldukça güçtür. Mevcut cerrahi yöntemlerin ötesinde yapay zekâ uygulamalarının konuşulduğu günümüzde, sürecin hemşirelerin bilgi ve beceri düzeylerinde bir değişim ve gelişimi de beraberinde getirdiği görülmektedir. Bu derleme, geçmişten günümüze cerrahi/cerrahi hemşireliğinde yaşanan değişim süreçleri ve meydana gelen gelişmeleri ortaya koymak amacıyla kaleme alınmıştır.
\end{abstract}

Anahtar Sözcükler: Cerrahi, cerrahi hemşireliği, tarih, minimal invaziv cerrahi işlemler, yapay zekâ.

\section{The Place of Surgical and Surgical Nursing from Past to Present}

\begin{abstract}
The greatest desire of man has been a long life and immortality. In an effort to realize this goal, the person has been exposed to many traumas and injuries in his struggle for life. This emerging picture has accelerated the development of surgery. Studies reveal that surgical practices are used for reasons such as treating disease, repairing and healing damage, as well as serving a number of religious purposes such as witchcraft. It has been stated that there are significant differences between the societies regarding the diagnosis of surgery and the methods used from the past to the present. Surgery, in the past which started with simpler applications such as trepanation, drainage, wound treatment, etc., today, with the rapid developments in science and technology, it has been replaced by some methods such as robotic surgery, transluminal endoscopic surgery etc. It is very difficult to predict the extent to which these unpredictable rapid changes in science and technology will affect surgical nursing. Beyond the current surgical methods, today, when artificial intelligence applications are discussed, it is seen that the process brings about a change and development in the knowledge and skill levels of nurses. This review has been written to reveal the processes of change and developments in surgical/surgical nursing from the past to the present.
\end{abstract}

Keywords: Surgery, surgical nursing, history, minimally invasive surgical procedures, artificial intelligence.

Derleme Makale (Review Article)

Geliş / Received: 24.07.2021 \& Kabul / Accepted: 12.09.2021

DOI: https://doi.org/10.38079/igusabder.973827

${ }^{*}$ Prof. Dr., Sakarya Üniversitesi, Sağlık Bilimleri Fakültesi, Hemşirelik Bölümü, Sakarya, Türkiye,

E-posta: daygin@sakarya.edu.tr ORCID https://orcid.org/o0oo-0003-4620-3412

*** Arş. Gör., Sakarya Üniversitesi, Sağlık Bilimleri Fakültesi, Hemşirelik Bölümü, Sakarya, Türkiye,

E-posta: ayselgul@sakarya.edu.tr ORCID https://orcid.org/0000-0002-0073-8916 


\section{Giriş}

Tarihin her döneminde insanoğlunun en büyük arzularından biri, uzun yaşama isteği ve ölümsüzlük olmuştur. Ancak ölüme boyun eğmek zorunda kalan insan, hastalık ve tedavilerine ilişkin cerrahi uygulamaları da içeren çok sayıda girişim deneyerek uzun yaşamı amaç edinmiştir

Ameliyat (el, el ile yapılan iş) anlamına gelen "chirurgia" sözcüğünden türetilen cerrahi, bedensel işlev ya da görünüşü araştırmak, patolojik durumu, hastalığı tedavi etmek, hasarı onarmak ve iyileştirmek ya da dini, kültürel kural ve düzenlemeleri yerine getirmek için eller, aletler ve birtakım tekniklerle insizyon oluşturularak yapılan eski bir uygulamadır ${ }^{2,3}$. Mağara dönemindeki insanların yaşamlarını sürdürmek amacıyla avlanmalarının travma ve yaralanmalara yol açması cerrahiye ivme kazandırmıştır. Bu dönemde insanların kanamaları durdurmak ve yaraları kapatmak amacıyla bazı yaprak ve otları kullandıkları bilinmektedir. Cerrahideki gözle görülür bu gelişmelere karşın, enfeksiyon, tümör, konjenital anomaliler vb. gibi birçok konunun belirsizliğini ve önemini koruduğu görülmektedir4.

Yapılan incelemeler, cerrahi uygulamaların hastalıkların tedavisinin yanı sıra büyücülük gibi birtakım dini amaçlara hizmet etmek amacıyla da kullanıldığını ortaya koymaktadır. Antik döneme ait kazılardan elde edilen, insan iskeletlerindeki eski kırık ve yara izlerinin varlığı, kişilerin kaderlerine terk edilmeyip tedavi altına alındığını göstermektedir5. Tıp doktorları tarafından uygulanan bu cerrahi operasyonların en önemli rolünün yaralı askerlerin tedavi edildiği savaş alanları olduğu da belirtilmektedir ${ }^{6}$.

Cerrahinin tanılanması ve birtakım yöntemlerin kullanılması toplumlara göre farklılık göstermektedir. Cerrahi tanı ve tedaviye ilişkin objektif ve sistematik bilinen en eski metin EdwinSmith Papirüs'tür. Tıp pratiğine yaklaşımına benzerliğiyle dikkati çeken bu metinde belirti ve semptomlar, tanı ve tedavi, muayene süreciyle ilgili birçok bilginin yer aldığı görülmektedir. Burada kosta kırıkları ve göğüs travmalarının cerrahi tedavisi, meme kanseri tanımı, kafa travmalarını tedavi etme süreçleri, birtakım nörolojik yaralanmalara ilişkin teşhis ve tedaviye yönelik cerrahi uygulamalar açılanmaktadır3,7. Geçmişten günümüze birçok cerrahi tekniğin geliştirilmesinde, cerrahi operasyonların steril ortamlara taşınması, minimal invaziv cerrahi, robotik teknoloji ve vücut boşluklarından uygulanan transluminal endoskopik cerrahi gibi pek çok önemli değişiklik meydana gelmiştir8-10. Değişen ve gelişen dünyada bilim ve teknolojide görülen hızlı değişimlerin cerrahi gelişmeleri ne boyutta etkileyeceğini belirlemek gerçekten zordur. Cerrahi bu kadar hızla gelişirken sağlık ekibinin üyesi olan cerrahi hemşirelerinin bilgi, beceri ve uygulama alanları da bu gelişmelere paralel olarak değişmekte ve gelişmektedir.

\section{Tarih İçerisinde Cerrahi/Cerrahi Hemşireliğinin Gelişimi}

Cerrahi, "hastalarm biyolojik ve fizyolojik fonksiyonlarm değiştirebilecek istemli travma yaratılması" olarak açıklanmaktadır. Cerrahi hemşireliği ise; "cerrahi ya da diğer invaziv girişimler uygulanan bir hastanin ameliyat öncesi, strası ve sonrası fiziksel ve biyopsikososyal tüm gereksinimlerinin belirlenerek planlı bir şekilde karşılandığ hemşirelik dalı"dır. Bireysel hasta tedavi ve bakımını planlar, kanıt temelli uygulamaları güvenli şekilde uygular ve değerlendiriri ${ }^{11}$.

Cerrahi hemşireliği iletişim, liderlik, ekip çalışması ve karar verme becerisi gibi bilişsel yeteneklerin yanı sıra çeşitli ekipman ve cihazlar ile yeni cerrahi teknik ve yöntemlerin kullanılmasını da gerektirir ${ }^{11}$. Bu bağlamda bilim ve teknolojideki gelişmelerin sağlık alanındaki hızlı yansımalarının cerrahi hemşirelerinin görev ve sorumluluklarını arttıracağı açıktır. 


\section{Tarih Öncesi Dönem}

Yapılan incelemeler cerrahinin ve birçok cerrahi tekniğin Taş ve Tunç Devrine kadar uzandığını ortaya koymaktadır. Tarih öncesi döneme ilişkin birçok veriye mağara resimleri, iskelet ve mumya incelemeleri sonucunda ulaşılmaktadır. Bu döneme ilişkin veriler, kafa travması, erkek sünneti ve savaş yaralarının iyileşmesi ile ilgili cerrahi deneyimlerin yaşandığını ortaya koymaktadır. Kazılar, trepenasyon, tümör eksizyonu, perforasyon, drenaj, amputasyon ve yara tedavisi gibi basit cerrahi işlemlerin yanı sıra sihir ve büyü gibi uygulamaların yapıldığını ortaya koymaktadır4,12. Dolayısıyla tarih öncesi dönemde tıp, cadı doktorların uyguladığı sihir, bitkisel ilaç ve batıl inançların bir karışımıydı. Bu bağlamda nöroşirurji cerrahisi oldukça uzun bir geçmişe sahiptir ve tarihteki en eski ameliyat olduğuna inanılan trepenasyon uygulaması için taş aletlerin kullanıldığı 12.000 yıl öncesine kadar uzanmaktadır. Bu uygulamanın epilepsi, kafa travması, şiddetli migren ya da zihinsel hastalıklar yaşayan insanlarda kötü ruhun serbest bırakılması için yapıldığına inanılmaktadır ${ }^{13}$. Ancak uygulanan cerrahi işlemler bazen iyi niyetli kişiler, beceriksiz uygulayıcılar ya da düşük nitelikte kişilerin ellerinde gelişme göstermiştir. Yapılan cerrahiler faydalı olmaktan ziyade cani ve barbar bir uygulama halini almıştır ${ }^{14}$. Mezopotamya'da Dicle ve Fırat nehirlerinin kıyısında yapılan incelemelerde birçok cerrahi alete rastlanmıştır. Taş, bronz ya da kemikten yapılan çeşitli cerrahi aletlerle yapılan ameliyatlar rahip ya da hekimler tarafindan gerçekleştirilmektedir. Bu döneme ilişkin Hammurabi Yasası'nda birçok cerrahi operasyonun uygulanma şekli ve cerrahi hatalara yer verildiği görülmektedir. Hindistan'da Susruta, İslam ülkelerinde ise Albucasis cerrahinin sembolü haline gelmişlerdir 15-17.

Mağara resimleri incelendiğinde cerrahların kafatası, dişler ya da kemikler üzerinde birçok ameliyatı gerçekleştirdikleri ortaya konulmaktadır. Tarih öncesine ait bazı cerrahi uygulama örneklerine Resim 1'de yer verildi. Yumuşak dokuya yapılan cerrahi işlemlere ilişkin kanıtların bulunmaması yumuşak dokular üzerinde cerrahi herhangi bir işlem yapılmadığı anlamına gelmemektedir. Cerrahi sonrasında bazı hastaların hayatta kaldığı belirtilmektedir3. Bu dönemde de başkasına bağımlı ve öz bakımını sürdüremeyen kişilerin ihtiyaçları başkaları tarafından karşılanmıştır. Ancak döneme ilişkin hasta bakımının nasıl ve kimler tarafından yapıldığına dair kesin kanıtlar bulunmamaktadır ${ }^{18}$.

Antik çağda cerrahi, cerrahi hemşireliği hakkında net veriler olmamakla birlikte insanlık tarihinin başlangıcına kadar dayanan tıbbi uygulamaların, insanların gelişimine paralel olarak bir formdan başka forma geçen yapıya sahip olduğu bildirilmektedir ${ }^{19}$.

Resim 1. Tarih öncesine ait cerrahi uygulama örnekleri ${ }^{2}$
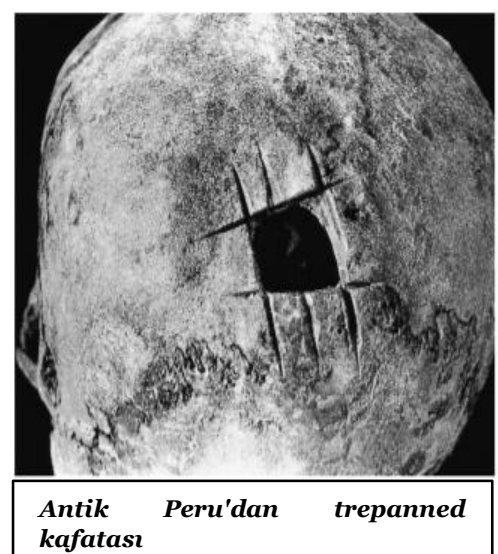

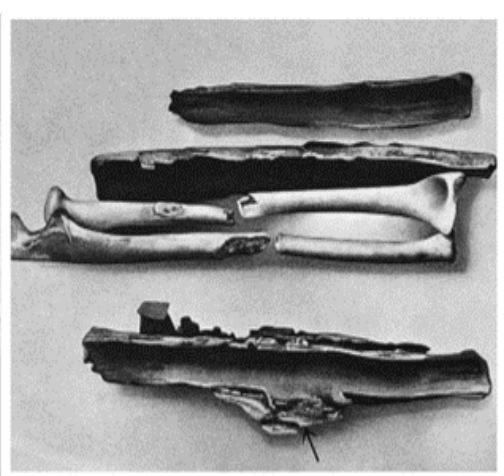

Mrsir kazlarmdan kalma ve yaklaşık MÖ 2450 tarihli, kabuk atelleri olan kurk önkol kemikleri

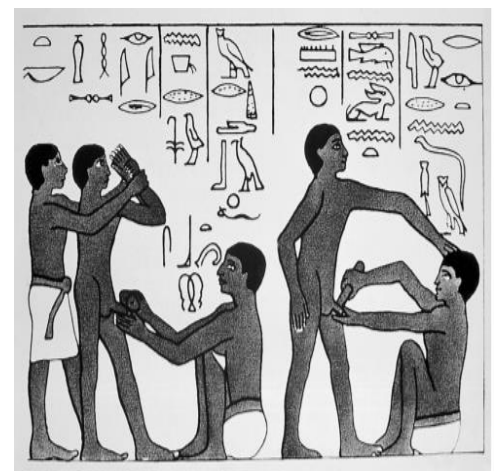

Bir sünnet sahnesinin mezar oymacılığı çizimi. Memphis'teki Sakkara Mezarliğı, Misır, MÖ 240o-300o. 


\section{Eski Mrstr Medeniyeti}

Cerrahiye ilişkin ilk kaynakların bu topluma ait olduğu düşünülmektedir. Tapınaklarda din adamlarının basit cerrahi operasyonları yaptıkları belirtilmektedir. Papirüslerde büyüden başka birçok yaralanma ve ağrıya ilişkin tedavi reçetelerinin olduğu görülmektedir. Kalp ve dolaşım sistemine ilişkin doğru bilgiler mevcuttur ${ }^{6}$. Eski Mısır medeniyetinin hasta bakımı ve tıbbın gelişmesine önemli katkıları olmuştur. Bu dönemde sanat ve bilimde etkili Tanrıların olduğu görülmektedir. Dini ayinler eşliğinde apse drenajı, kırık, çıkık ve yanık tedavilerinin yapıldığı, büyü ve ilaç uygulamalarının hastalık cinlerini uzaklaştırmak amacıyla kullanıldığı belirtilmektedir ${ }^{18}$.

Mısır medeniyetinde tedaviden daha çok doğru tanılamaya önem verdikleri ve bilgi düzeylerinin oldukça iyi düzeyde olduğu görülmektedir. Bu toplumda dikkati çeken konu, cerrahların temizlik ve hijyene önem vermeleridir. Yapılan incelemeler, çakmaktaşı ve bronzdan cerrahi aletlerin yapıldığı, en eski cerrahi işlemlerden birinin sünnet olduğunu ortaya koymaktadır. Bu dönemde hemen hemen her organ ve hastalığa özgü uzman varlığı, doktorlar arasında branşlaşmanın olduğunu da ortaya koymaktadır ${ }^{19}$. Ancak bu döneme ilişkin metinlerde de hemşirelikle ilgili herhangi bir belge ya da bilgiye rastlanmadığ bildirilmektedir ${ }^{20}$.

\section{Mezopotamya}

Mısırlıların aksine Babil doktorları bilimsel yöntemlerinin yanı sıra din ve sihri kullanan cadılar olarak nitelendirilmiştir. Bu dönemde Hammurabi yasalarının varlığı cerrahinin gelişimini etkilemiştir ${ }^{21}$. Yasa, üst sınıf hastalara yanlış/başarısız ameliyat yapılması durumunda cerrahın ellerinin kesilmesini ya da öldürülmesini zorunlu kıldığından cerrahi operasyonların başarısı önemlidir. Ancak bir köylüde cerrahi başarısız olduğunda ise sadece para cezası uygulandığı görülmektedir. Bu yüzden cerrahlar birçok cerrahi tekniği köylüler üzerinde denemişlerdir ve el becerisi yüksek, başarılı cerrahi tekniklere sahip doktorların yetişmesi sağlanabilmiştir3.

\section{Hint Medeniyeti}

Günümüzde Hint medeniyetinin tıbbi uygulamaları hakkında kesin bir veri bulunmamasına karşın tüberküloz, öksürük, çiçek hastalığı gibi birçok hastalık ve bitkisel ilaçtan bahsedildiği görülmektedir. Hint mitolojisinin toplumda etkili olduğu anlaşılmaktadır. Hint mitolojisinde Güneşin cerrah ve hekim olan oğulları olduğuna inanılmaktadır. Bu inanış toplumun cerrahide ilerlemesine katkı sağlamıştır ${ }^{18}$. Hintliler, özellikle genel, plastik ve kulak, burun ve boğaz ameliyatları ile cerrahi aletler ve teknolojilerdeki gelişmeleriyle ön plana çıkmışlardır. Özellikle plastik cerrahide ve cerrahi tekniklerde geleneksel Hint tıbbının babası olarak Sushrutha Benare bilinmektedir. 120'den fazla alet ve 300'den fazla cerrahi tekniği ortaya koyduğu ve cerrahiyi sekiz kategoriye ayırdığı, plastik ve katarakt ameliyatı, amputasyon, litotomi, hemoroidektomi, rinoplasti ve sezeryan gibi birçok operasyonu tarif ettiği görülmektedir ${ }^{14,22}$.

Hint tıbbında yaşanan gelişmelerde Budizm’in de etkisinin olduğu görülür. Budizm’in zayıflamasıyla birlikte ortaya çıkan sınıf farklılıkları hasta bakımı ve tıbbın gelişmesini olumsuz etkilediği görülmektedir. Kadınların toplumdaki yerinin sadece ev kadını statüsünde kaldığı belirtilmektedir ${ }^{18}$. Dini inanışların etkisiyle mumyalama yapılması, ölümden sonra bedenin korunması algısını ön plana çıkarmış ve diseksiyon uygulamalarına engel olmuştur. Eviserasyonların bel insizyonlarıyla yapıldığı, beynin burundan gönderilen bir kanca ile çlkarıldığı görülmektedir. Anatomik bilgilerin sadece yüzeyel organlardan elde edilen bilgilerle sınırlı olduğu anlaşılmaktadır. Sünnet uygulamalarının oldukça yaygın olduğu, yaraların koterizasyonu, emici malzemelerle kapatılması, yaralarda bal ve yağ kullanılması gibi birçok uygulamayı gerçekleştirdikleri belirtilmektedir ${ }^{14}$. 
Hindistanda ilk kez M.Ö. 8oo'lü yıllarda hemşirelik mesleğinin prensip ve uygulamaları ile ameliyathane hemşireliğinden bahsedilmiştir. Bu dönemde hekim Sushrutha'nın cerrahi uygulamalarda hemşireleri asistan olarak çalıştırdığı görülmektedir. Bu dönemde yapılan ameliyatların, büyük bir salonda gözlemciler önünde gerçekleştirildiği ve asepsi kurallarına uyulmadığı bilinmektedir. Bu dönemden 20. yüzyıla kadar Hint tıp tarihinde hemşire/hemşire/cerrahi hemşireliğine ilişkin herhangi bir veriye rastlanmamıştır²0.

\section{Çin Medeniyeti}

Çin tıbbının din etkisinde iki teori üzerine kurulduğu görülür. İlk teori, hastalıkları yaşamın temeli edilen Yin ve Yang arasındaki dengenin bozulması olarak açıklar. İkinci teoride ise, insan bedeni gökyüzü ve yeryüzü ortamından etkilenen bir varlık olarak tanımlanır. Organizmada dolaşımın düzgün olduğu zamanlarda uyum ve dengenin olacağı, bireyin sağlıklı olduğu belirtilmektedir. Hastalıklar içsel bir durum olarak kabul edildiğinden etkilenen organa müdahale etmek yerine Yin ve Yang arasındaki dengenin yeniden sağlanmasına çalışılmıştır ${ }^{14}$. Hasta bakımında homeostazisin bir göstergesi olan nabız saymanın önemine değinmişler ve vücudun farklı yerlerinde 100-200 arasında değişen atım sayısı olabileceğine inandıkları için hasta muayenelerinin uzun sürdüğü belirtilmektedir ${ }^{18}$. Cerrahi temel tıp bilimlerinden dışlanmıştır. İnsan vücudu kutsal kabul edildiğinden cerrahi müdahaleler ilaçlara bağlı kalmış, organizmanın fiziksel sorunlarından ziyade fonksiyonel yapısına odaklanılmıştır ${ }^{14}$.

Çin tıbbının öncü isimlerinden Tuo Hua'nın anestezi, cerrahi ve akupunktur uygulamasına ilişkin önemli katkıları olduğu görülmektedir. Anestezi eşliğinde laparatomi ve transplantasyon ameliyatları, splenektomi ve kolostomi gibi birçok batın ameliyatını gerçekleştirdiği bilinmektedir ${ }^{23}$.

\section{Yunan Medeniyeti}

Yunan Medeniyetinde tıp ve hasta bakımının gelişimi mitolojiyle başlamış ve Hipokrat ile pozitif bilime dönüşmüştür. Yunanlılarda güneş ilahı olan Apollo sağlık ve tıp ilahıdır ve oğulları tanınmış cerrahlardırir. Toplumdaki cerrahi operasyonlar temel olarak savaş yaralanmalarına ilişkindir. Yunanlılar diğer medeniyetlerden elde edilen bilgi ve deneyimlerden yararlanmışlar, yara kapanması, drenaj, kırıklar, turnike uygulamaları, amputasyonlar vasküler sütür gibi birçok cerrahi teknikte başarılı sonuçlar elde etmişlerdir. Eski Yunan medeniyetinin tıp bilimine önemli katkılarından biri Latincenin tıbbi alanda kullanılmasını sağlamaları olmuştur. Bu dönemde cerrahların özel bir branş olarak görev yapmaları savunulmuş, ilaç tedavisinin etkili olmadığı yaralanmalarda başvurulan hekimler oldukları görülmektedir ${ }^{4}$. Toplumda ailedeki kadınların hasta bakımı ve sağlığın korunmasına ilişkin görevleri vardır ve hemşireliğin atasını oluşturmuşlardır ${ }^{18}$. Bu dönemde mitolojide Tanrı olarak kabul edilen Yunan hekimi Aesculapius'un kızı Hijyen'in, tapınakta hastalara bakım hizmeti verdiği görülmektedir. Bu döneme ilişkin örgütlü bir hemşirelik grubunun olduğunu gösteren herhangi bir yazılı kaynağa rastlanmamaktadır ${ }^{24}$.

\section{Roma Uygarhğı}

Romalılarda cerrahi Yunanlılarda olduğu gibi savaş yaralanmalarını tedavi etmek amacıyla oldukça gelişmiştir. Özellikle ameliyathanelerin gelişimi ve yaralı askerlerin ameliyathaneye götürülmesi için ambulans benzeri vagonların kullanılması dikkat çekmektedir. Bu dönemde yara cerrahisi o kadar gelişmiştir ki, sadece bu alanla ilgilenen doktorlara çeşitli unvanlar verilmiştir3. Romalı kadınların toplum yaşamına etkin bir şekilde katıldıkları, yolculara ve yoksul hastalara kendi evlerinde bakım verdikleri bilinmektedir. Birçok toplumun aksine bakım vericiler zengin ve asil kadınlardan oluşmaktadır²4. Romalılarda hastanelerde daha çok erkeklerin çalıştığı, 
kadınların hemşireliği sanat olarak uyguladıkları ve etkili olamadıkları görülmektedir ${ }^{18}$.

\section{İslam Toplumlarn}

Avrupa karanlık çağa girdiği dönemde İslam medeniyetleri bilimde oldukça ileri gitmişlerdir. Döneminin en iyi doktorlarından birisi olan İbni Sina, Batı dünyasında tıp ve cerrahi alanında Avicenna olarak bilinmektedir. Yazdığı kitaplar uzun bir süre Batı dünyasında ders kitabı olarak okutulmuştur. Matbaanın icadından sonra İncil'den sonra en çok basılan kitap İbni Sina'nın kitabı olmuştur ${ }^{25}$. Hastalıkların teşhis ve tedavisi için cerrahi koğuşlar oluşturan İbni Sina birçok cerrahi yöntemin gelişimine katkıda bulunmuştur. Her ne kadar yazılı bir kaynak olmasa da yapılan sözlü bildirimler İbni Sina'nın kolesistektomi ameliyatı yaptığı yönündedir3.

Tıp dünyasında önemli katkılarıyla bilinen bir diğer isim Ebu Bekir Muhammed İbn Zekeriya Razi'dir. Kolik, böbrek ve mesane taşlarının çıkarılması, katarakt ve diğer göz hastalıklarının cerrahi tedavisini tarif etmiş ve yeni yöntemler geliştirmiştir. Bulaşıcı hastalıklara ilişkin yaptığı çalışmaların yanı sıra cerrahiye pek çok katkısı olmuştur ${ }^{26}$.

Batıda Albucasis olarak bilinen Ebu el-Kasım Rönesansın sonuna kadar Avrupa cerrahisini şekillendirmiştir. Yazdığı kitaplarda böbrek taşlarının çıkarılması, göz, kulak, burun ve boğaz ameliyatları, yaralarda primer kapatma, debridman, birçok kanser türünün cerrahi tedavisi ve plastik cerrahiye ilişkin birçok cerrahi yöntemini açıklamaktadır ${ }^{27}$.

İslamiyet ile birlikte hasta bakımı önemli bir hale gelmiştir. Savaşlarda yaralı askerlere bakan kadınların olduğu, hatta yaralı ve hasta bakımı için ilk kadın topluluğunun Hz. Muhammed zamanında kurulduğu bilinmektedir. Buna rağmen hemşireliğin anlam ve önemi çok geç anlaşılmış olup hasta bakımı, hastanın yemeğini yedirmek ve ağır işleri olan kişilere yardım etmek ile sınırlı kalmıştır ${ }^{18,24}$.

Türk hekimleri değerli çalışmaları ile önemli katkılar sağlarken, Osmanlı'da kadınların sosyal yardım işlerinde ve hasta bakımında gönüllü olarak çalıştıkları görülmektedir. Ancak bu alanda herhangi bir eğitim almadıkları için hemşirelik mesleğine herhangi bir katkı sağlayamamışlardır. Modern anlamda hemşirelik mesleğinin kurulması ve gelişim göstermesi ise Cumhuriyet dönemiyle birlikte olmuştur ${ }^{18,24}$.

\section{Avrupa Medeniyeti}

Karanlık çağ olarak da bilinen Ortaçağ, Avrupa bilimi ve tıbbı için kötü bir dönemdir. Batılı dini oteritelerin bilime karşı çıtıkları, bilimsel araştırma için insan vücudunun ve cesetlerin incelenmesinin yasaklandığı bu dönemde yeni fikirler sapkınlık olarak kabul edilmiş ve dinsel tıp desteklenmiştir. Tedavinin Tanrı'nın iradesinde olduğu düşünüldügünden cerrahi operasyonlar değerli görülmemiştir. Hijyen uygulamaları çok kötüdür ve cerrahi son derece acı veren bir uygulamadır ${ }^{19}$.

Anatomist Andreas Vesalius'un Rönesans döneminde cerrahi tekniklerin ilerlemesinde önemli katkıları olmuştur. Batıda üniversitelerin yükselişe geçmesi cerrahi bilginin ilerlemesini sağlamıştır. Ancak Avrupa ülkelerinde tıpta görülen gelişmeler aynı hızda cerrahide gerçekleşmemiştir. Karanlık çağda uygulanan sansür nedeniyle cerrahi, doktorun işi olarak görülmemiştir. Bu nedenle cerrahi teknikleri öğrenen insanlar müzik, eğlence, saç kesme gibi birtakım becerilerle uğraşmışlardır. Dolayısıyla kasaba ve köylerde cerrahi operasyonlar yapan berber cerrahlar ortaya çıkmıştır. Ancak berber cerrahlar kullandıkları tekniklerin ilkel ve ağrılı olması ve komplikasyonlara yol açması nedeniyle popüler değildir. Bu bağlamda önemli gelişme cerrahların akademik bir topluluk haline gelmesi için İngiltere'de kararname imzalanması olmuştur. 3 Özellikle amputasyon yoğun olarak yapılan bir cerrahi olmasına karşın ağrı ve cerrahi 
alan enfeksiyonları nedeniyle istenilen düzeyde ilerleme kaydedilememiştir. Amputasyon uygulamasında ağrının azaltılması için bitkisel anesteziklerin kullanılmaya başlanmıştır ${ }^{12}$.

Orta Çă̆’da Avrupa'da Hristiyanlık dininin hasta bakımını etkilediği görülmektedir. Kilise ve manastırlara bağlı olarak sosyal hizmetlerde çalışan kadınlara dekones, erkeklere ise dekon denmiştir. Eşit haklara sahip bu kişiler, herhangi bir eğitim almamışlar, kilise/manastır içinde ve dışında ziyaretçi hemşirelik ve hasta bakımı gibi sosyal görevler üstlenmişlerdir ${ }^{18,24}$. Cerrahi bakım kapsamında haçlı seferleri sırasında erkeklerden oluşan bir kuruluşun var olduğu, becerikli bir şekilde yara temizleme ve sargı yaptıkları bildirilmektedir ${ }^{24}$. Avrupa'da Hristiyanlığın hızla yayıldığı bu dönemde Arap ülkelerinden esinlenerek “Tanrı'nın evi” olarak da adlandırılan yolcu ve hacıların seyahat süresince barınabilecekleri, bakım hizmeti de verilen ve gönüllü kadınlardan oluşan ilk han Paris'te kurulmuştur. Bu kadınların belirli bir eğitimden geçtikleri, özel beyaz kıyafetler giydikleri ve kep taktıkları belirtilmektedir. Bu kadınların hastalara ilaç vermek, yara bakımı ve fiziksel ve dinsel ihtiyaçlarını gidermek gibi birtakım görevleri vardır ${ }^{24}$.

\section{Günümüzde Cerrahi}

Cerrahi tekniklerde modern çağın başlangıcını Louis Pasteur'un çalışmaları oluşturmuştur. İlerleyen dönemde Joseph Lister enfekte yaralarda mikroorganizmaları tespit etmiş ve enfeksiyon/ların etyolojisini oluşturduğunu kanıtlamıştır4,20. Bu mikroorganizmaları yok edebilmek için birtakım antiseptik önerilerinde bulunmuş ancak bu antiseptiklerin dokuya zarar vermesi ve mikroorganizmaların karbolik aside adapte olması nedeniyle tercih edilmemiştir3. Semmelwise Lister mikroorganizmaların keşfinden önce ellerin temizlenmesi gerektiğini ortaya koymuş olsa da o dönemde bilimsel kanıtlar desteklenmediği için taraftar bulamamıştır. Ancak yaygın olarak kullanılan karbolik asit ihtiyacı karşılamada yetersiz kaldığı ve basınçlı buharla sterilizasyon teknikleri uygulanmaya başlandığında popüler hale gelmiştir. 1867 yılında Cerrahi Uygulama Antiseptik Prensipleri adıyla bu teknikler belgelenmiştir3.

Cerrahi tekniklerin ilerlemesindeki en büyük engel ağrıdır ve nitröz oksitin kullanılmaya başlamasıyla cerrahinin konumu farklı bir noktaya taşınmıştır. 19.yüzyılın ikinci yarısından itibaren farklı bir boyut kazanan cerrahi, John Snow'un ameliyat sırasında ağrıyı önlemek için eter ve kloroform kullanmasıyla hız kazanmıştır. Dolayısıyla cerrahlar da vücudun birçok farklı bölgesini inceleme firsatı bulmuşlardır ${ }^{28}$.

On dokuzuncu ve 20.yüzyılın başlarında, eğitim sınıfı olarak da kullanılan birçok ameliyathane yapılmıştır. Bu dönemde dünyanın birçok yerinde açık cerrahi operasyonlar yapılmaya başlanmıştır. Cerrahi operasyonların öğrenciler ve halk tarafından izlenmesine imkân tanıyan bu ameliyathaneler ilerleyen dönemde yenilenmişlerdir. Genel cerrahi, ortopedi, pediatri, obstetrik ve jinekoloji gibi pek çok alanda cerrahi teknikler denenmiştir. Organ nakli, modern cerrahi tekniklerin gelişiminde önemli bir basamaktır. Transplantasyon için cerrahi teknikler cerrah Vladimir Demikhov tarafından geliştirilmiştir. Kendisinin bir köpeğe baş nakli yapması ses getirmiştir. Ayrıca akciğer, kalp, renal ve hepatik transplantasyonları gerçekleştirmiştir29.

\section{Minimal İnvaziv Cerrahi Teknikler}

Cerrahi inovasyon ciddi düzeyde iyatrojenik etkiyi azaltma, hasta güvenliği ve yaşam kalitesini arttırmayı amaçlar. Bu bağlamda yaklaşık 30 yıl önce minimal invaziv cerrahi yöntemlerin ortaya çımması birçok yeniliği beraberinde getirmiş ve cerrahların ellerini hasta üzerinden çekmesine yol açmıştır8. Minimal invaziv cerrahi, büyük insizyonların gerek olduğu açık cerrahinin aksine, küçük insizyonlar ya da doğal delikler yoluyla hedef organa ulaşılmasını sağlayan cerrahi aletlerin kullanılması sürecidir. Bu cerrahide amaç periferik doku hasarını en aza indirmek, güvenli ve hızlı bir operasyon sunmaktır. Özellikle hasta güvenliği, iyileşme süresi, daha kısa hastanede yatış 
süresi, daha az komplikasyon ve ağrı gelişimi ve olumlu psikolojik bir etki gibi nedenler yaygın olarak kullanılmasına neden olmaktadır. Buna ek olarak azalan cerrahi travma, cerrahi alan enfeksiyonları ve herniasyon, günlük yaşam aktivitelerine daha hızlı dönüş ve daha iyi kozmetik sonuçlara sahip olduğu belirtilmektedir30-32. Ancak el-göz ekseni ayrık olduğu ve ameliyat alanı derinlik algısı azaltılmış 2D monitör aracılığıyla gerçekleştirildiği için görsel dürtü kaybı ve dokunsal geri bildirimin oldukça sınırlı olması söz konusudur. Bu nedenle doku sertliği, bir nodül varlığı ya da vasküler titreşim gibi önemli bulguların kaybı söz konusu olabilmektedir. Ayrıca sınırlı insizyon hattı, traksiyon, etkilenen organı açığa çıkarma ve endoskopik aletleri sık sık değiştirme ihtiyacı kişilerde perforasyon ve kanama riskinin, olası hasta rahatsızlığının artmasına ve uzun çalışma sürelerine yol açabilmektedir8 ${ }^{8}$. Buna ek olarak iyatrojenik sinir hasarı, kanama ya da trombozla sonuçlanan nörovasküler yaralanmalar olabilmektedir. Olası yüksek komplikasyon oranları nedeniyle yeniden ameliyat riski daha fazladır ${ }^{2}$. Ancak cerrahi ekip bu prosedürlere aşina hale geldikçe operasyonlar daha hızlı gerçekleştirilebilecektir.

\section{Robotik Cerrahi}

Minimal invaziv cerrahi tekniklerin 1980'li yılların sonlarında gelişmesi, cerrahların ameliyatta doğrudan manipülasyonunu büyük ölçüde azaltmıştır. Vücuda küçük insizyonlarla müdahaleyi kolaylaştıran bu sistem cerrahide önemli gelişmeleri de beraberinde getirmiştir. Bu noktada minimal invaziv cerrahi tekniklerin robotik cerrahiye zemin hazırlayan geçişli bir teknoloji olduğu söylenebilir9.

Ameliyathanelerde 1985 yılında sterotaktik beyin biyopsisi yapmak için ilk tıbbi robotların kullanılmasından bu yana robotiklerin gelişimi etkileyici düzeyde devam etmektedir33. Bu süreçte birçok başarılı vaka gerçekleştirilmiş ve robotik teknolojilerin cerrahi aletlerle entegrasyonunda ilerlemeler kaydedilmiştir34. Sağlık sisteminde robotikler tıbbi teşhis ve tedavi, rehabilitasyon, hastalara koruyucu ve önleyici programlarda destek sağlama vb. gibi hizmetleri sağlamak amacıyla kullanılan sensör bilgisi analizine dayanan ve mekatronik işlemler yapabilen sistemler olarak açıklanmaktadır33. Robotların ameliyatta kullanılmasında iki temel hedef bulunmaktadır: Uzaktan müdahaleyi sağlamak, cerrahi işlemi eksiksiz ve tam olarak tekrarlı gerçekleştirebilmek. Bu bağlamda ilk robotik cerrahi uygulaması, 1985 yılında PUMA ile gerçekleştirilmiştir. Güç ve dokunsal geri bildirim eksikliği, yüksek maliyet gibi istenmeyen etkilerine karşın, stabil ve büyütülmüş görüntü, $3 \mathrm{D}$ görüş ve hareketi artırma gibi birçok özelliği laparoskopik cerrahiye özgü birçok sınırlamanın ortadan kalkmasını sağlamıştır35.

Tıbbi robotların sağlık sisteme sağladığı avantajları; yeni, iyi ve güvenilir tedaviler sunması, doğru geometrik ölçüde cerrahi operasyon yapılabilmesi, yorgunluk gibi durumların söz konusu olmaması, hafif ve modüler yapısı taşınabilir özelliği ve uzaktan müdahale yapılabilmesi, ayrıntılı bilgi kaydedebilme, geleneksel yöntemlere kıyasla daha etkili olması, daha az ağrı ve hızlı iyileşmenin sağlanması, başlangıçtaki maliyetleri yüksek olsa da olumlu sonuçları nedeniyle genel sağlı bakım maliyetini azaltması, zor/erişilemeyen alanlarda operasyonun gerçekleştirilebilmesi, bağımsız ve sosyal yaşama dönmede olumlu etkilerinin olması ve özellikle yaşlıların günlük ve sosyal yaşam aktivitelerini gerçekleştirmesine, bakım süreçleri ile sağlık ve hastalık bilgilerinin takibine robotik sistemlerin katkılarının olması sayılabilir35-42.

\section{Yapay Zekâ}

Yapay zekâ uzun bir geçmişe sahip olmasına karşın modern anlamdaki yeniden dirilişi " makine öğrenimi” olarak bilinen birtakım gelişmelerle birlikte gerçekleşmiştir43. Yapay zekânın her geçen gün hızla gelişimi, sağlık hizmetlerinde de bir dönüşümü beraberinde getirecektir. Bu teknolojinin hasta bakımı için potansiyel etkileri göz önüne alındığında hemşirelerin yapay zekâ 
kavram/larına ilişkin belirli düzeyde bilgi ve beceriye sahip olmasının önemi ortaya çıkmaktadır.

Yapay zekâ, görsel algı, ses tanıma, karar verme ve/veya dil çevirisi gibi tipik olarak insan zekâsı gerektiren birtakım görevleri tamamlayabilen bilgisayar sistemlerinin gelişimi ve teorisi olarak açıklanır. Daha basit tanımıyla; bir makinenin akıllı insan davranışlarını taklit etme yeteneği olup, makine öğrenimi, bilgisayarla görüş ve doğal dil işleme teknolojilerini bir araya getiren bir terimi temsil eder $43-45$.

Yapay zekâ destekli otomasyonun bir sonucu olarak, tarım, seyahat, medya vb. gibi diğer birçok ekonomik sektörde önemli iş kayıplarının yaşandığı belirtilmektedir. Ancak yapay zekânın, kısa vadeli dönemde diğer sektörlerde olduğu gibi hemşirelikte de benzer bir etkiye sahip olması olası değildir. Çünkü bu teknolojiyle birlikte rutin, tekrarlayan ve öngörülebilir görevler genellikle otomatikleştirilmiştir. Oysaki hemşirelik uygulamalarının çoğu rutin değildir ve öngörülemez. Ancak bu teknolojinin hemşirelik mesleğindeki olası etkileri yadsınamaz43.

\section{Ses ve Yüz Tanma Yazlhmı:}

Elektronik sağlık kayıtlarındaki klinik dokümantasyon, sözel iletişime kıyasla oldukça zahmetli ve verimsizdir. Bu bağlamda yapay zekâ destekli teknolojilerin önümüzde yıllarda hemşirelerin klavyeye olan bağımlılığını önemli ölçüde azaltması beklenmektedir. Ayrıca yapay zekâ kullanılarak birçok elektronik kaynaktan verilerin toplanmasına benzer şekilde, bu sistemle hemşireler için notlar hazırlanabilir ve vardiya değişimlerinde özet rapor olarak sunulabilir, hastalarla paylaşlabilir. Head-up bilgisayar görüntüleme gözlükleri sayesinde hemşirelerin hastaları kapsamlı bir şekilde değerlendirmesi söz konusu olabilir.

\section{Kișisel Sanal Asistan:}

Sağlık sisteminde hastalara ilişkin birçok farklı verinin saklanması nedeniyle kişilerin gerçek zamanlı ve bütüncül bir bakış açısıyla değerlendirilmesi oldukça güçtür. Özellikle risk altındaki hastaların erken teşhis edilmesi ve önleyici tedbirler alınabilmesi için hastalara ilişkin tıbbi verilerin bir araya getirilmesi oldukça önemlidir. Bu bağlamda yapay zekâ destekli sanal asistanların oluşturulmasına ilişkin birtakım çalışmalar sürmektedir.

\section{Robotik ve Bilgisayarla Görü:}

Hemşireliğin rutin bir işleyişe sahip olmaması nedeniyle robotların meslekte kullanımı oldukça yavaş olmuştur. Hemşirelikte, hastaların merdiven çıkmasına yardımcı olan dış iskeletler, bir odaya girerek, yatan hastayı bir uzmana bağlayabilen telepresence robotları, malzeme teslimini gerçekleştiren ve huzurevlerinde yaşlılara yardımcı olan robotlar, hatta hastaların saçlarını yıkayabilen robotların kullanılmasıyla yaygınlaşmıştır. Ancak günümüzde çok daha gelişmiş robotlar hastanelerde aktif olarak kullanılmaya başlanmıştır. Bu robotlar kendi kendine birtakım görevleri yerine getirebilen otonom özellik gösteren yapılardır43. Dolayısıyla yapay zekânın hemşirelik mesleğine etkileri oldukça hızlı ve değişkendir. Sadece birkaç yıl önce imkânsız gibi görünen pek çok şey, bugün olağan durumlar arasında yerini almıştır.

\section{Günümüzde Cerrahi Hemşireliği}

İlk çağlardan itibaren bireylerin sağlık sorunları ve bakım ihtiyaçlarının çözümünde ailedeki kadınların önemli bir role ve etkiye sahip olduğu bilinmektedir. Kayıtlarda cerrahi hemşireliğine ilişkin yeterli bilgiye rastlanılmamasına karşın, şarap, yă̆ vb. ürünlerle pansuman, bandaj yapma, hasta bireyin diyetine özen gösterme, laksatif kullanımı vb. gibi birtakım uygulamalara yer verildiği görülmektedir4.

Modern hemşirelik, ilerleyen süreçte tıpta yaşanan gelişmeler ve hastanelerin kurulmasıyla 
birlikte ivme kazanmıştır. 20. yüzyılın başında Amerika'da hastalara hizmet vermek üzere farklı uzmanlık dallarına (dahiliye, cerrahi, kadın doğum vb.) ilişkin kliniklerin kurulması, her bir klinikte görev alacak yetkinlik ve beceride hemşirelerin yetiştirilmesini gündeme getirmiştir ${ }^{4}$.

Florence Nightingale temiz çevre ve temiz su koşullarının iyileştirilmesi ve asepsi kurallarına uyulması çabaları ile enfeksiyon oranlarını önemli ölçüde azaltması cerrahi hemşireliğinin önemini ortaya koymuştur46-48. 1860 yllında hemşire okulunun açllmasına öncülük eden Nightingale sayesinde mesleğin önemi anlaşılmış ve sonrasında birçok hemşirelik okulu açılmıştır ${ }^{8}$. Ameliyata hazırlık, bandajlama, hemostaz ve cerrahi aletler gibi konular, 1875'li yıllardan sonra hemşirelik derslerine eklenmiştir46. 1880'li yllardan itibaren ameliyathaneler hemşirelerin çalışma alanları olarak görülmüş, ameliyathane hemşireliği uzmanlık alanı olarak önem kazanmış ve cerrahlarla birlikte görev almışlardır4,46. Geçmişten günümüze bazı cerrahi uygulama örneklerine Resim 2'de yer verildi. 1890'lı yıllarda “ameliyat sırasında cerraha sünger uzatma ve sargı beziyle yardım etme” gibi görevlerin cerrahi hemşirelerine verildiği, 1916 yılına gelindiğinde ise Smith’in ameliyatta ilk kez maske ve kep giydiği görülmektedir. Hastadan öykü alma, çevre düzenlemesi ve hastaların ameliyata hazırlanması gibi görevler 1900-1919 ylları arasında hemşirelere verilmiştir ${ }^{46}$.

Resim 2. Geçmişten günümüze cerrahi hemşireliği uygulama örnekleri48

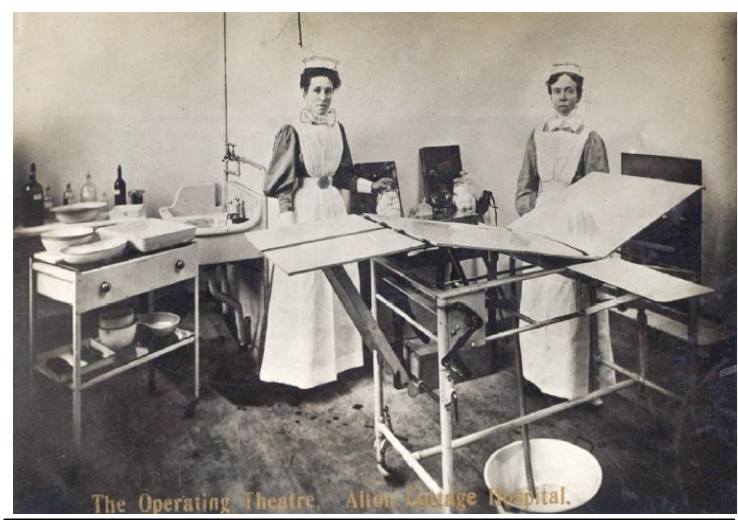

Alton Cottage Hastanesi ameliyathane, Hampshire, Birleșik Krallk (189o-1910)

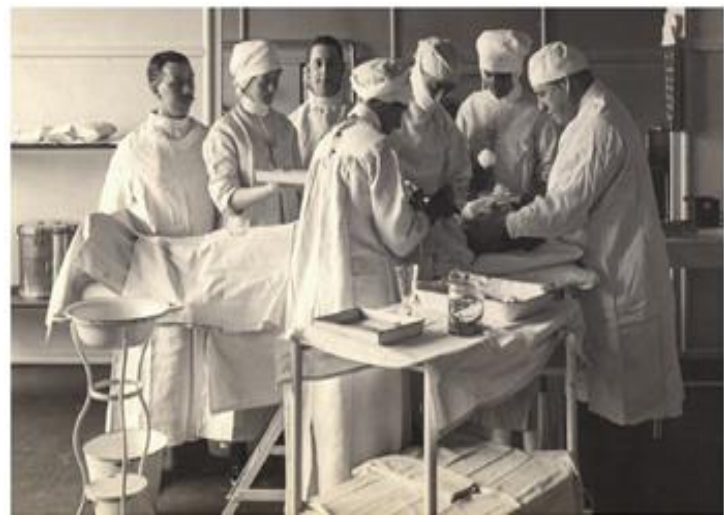

King George Askeri Hastanesi'nde ameliyat masasinda yatan hastaya bakan cerrahlar ve hemşireler, Londra, Ingiltere (1915)

Cerrahi hemşireliğii, 1930'lu yıllarda "cerrahi girişim uygulanan hastalara bakım veren hemşire" olarak görülmeye başlanmıştır. 1945 yılında M. Crawford ameliyathanede sirküle ve scrub kavramlarını açıklamıştır 46 .

Ülkemizde ise modern hemşireliğin öncüsü Safiye Hüseyin Elbi, Besim Ömer Paşa'nın hasta bakıcı kurslarına katılmış ve birçok savaşta gönüllü olarak askerlerin bakımında görev almıştır49. $\mathrm{Bu}$ savaşlarda, çevre temizliği (sanitasyon), kan nakli, anestezi, yara bakımı ve debritmanı, nazogastrik sonda takılması, şoka müdahale, yoğun bakım ve psikolojik destek verilmesi gibi uygulamalarla hemşireliğin temelleri atılmıştır ${ }^{6}$.

Bugün profesyonel anlamda cerrahi hemşireliği, cerrahi girişim öncesi, sırası ve sonrasında bireyin fizyolojik, psikolojik ve sosyokültürel ihtiyaçlarının giderilmesi, iyilik halinin yeniden sağlanması ve geliştirilmesinde, hastanın bireyselleştirilmiş bakımında önemli sorumluluklar alan bir meslektir46,50. 


\section{Sonuç}

Başlangıcı insanoğlunun var oluşuna kadar dayanan cerrahi, geçen süre zarfında oldukça hızlı bir değişim ve gelişim örneği göstermiştir. Tarih öncesi dönemde basit uygulamalarla başlayan bu süreç, günümüzde bilim ve teknolojideki hızlı gelişmelerle birlikte yerini daha az ağrı, daha az travmatizan etki ve elle manipülasyonların minimal düzeye indirildiği çeşitli yöntemlere bırakmıştır. Bugün yapay zekâ uygulamalarının konuşulduğu günümüz dünyasında, cerrahi gelişmelerin geleceğini öngörmek gerçekten güçtür. Bu bağlamda mevcut ve/veya potansiyel eğilimlerin bilinmesi ve bunların dikkate alınması cerrahi hemşirelerinin gelişimi için oldukça önemli bir konudur. Hemşirelerin tedavi ve bakım uygulamalarında değişimlere ayak uydurması gerekliliği göz önüne alındığında, sunulan hemşirelik eğitimlerinde meydana gelen değişimlere yönelik yapılandırma çalışmalarına ihtiyaç olduğu anlaşılmaktadır.

\section{KAYNAKLAR}

1. Mandacı Uncu E. Eski Mezopotamya'da tip. History Stories. 2013;5(5):107-117.

2. Ellis H. Surgery in prehistoric times. The Cambridge Illustrated History of Surgery. 2009;1-10.

3. Qayumi K. Surgical techniques: Past, present and future. Surgical Techniques Development. 2012;2(9):29-36.

4. Aksoy G. Cerrahi ve cerrahi hemşireliği. In: Aksoy G, Kanan N, Akyolcu N, eds. Cerrahi Hemşireliği I. İstanbul: Nobel Tıp Kitabevi; 2017:1-38.

5. Yalçın BM, Ünal M, Pirdal H, Selçuk Y. Anadolu tıp tarihi - bölüm I. Türk Aile Hek Derg. 2016;20(1):33-44.

6. Akar M. Cerrahi tekniklerin resimsel anlatımı. Art-Sanat. 2015;3:15-43.

7. Feldman RP, Goodrich JT. The Edwin Smith Surgical Papyrus. Child's Nerv Syst. 1999;15:281-284.

8. Marescaux J, Diana M. Inventing the future of surgery. World Journal of Surgery. 2015;39(3):615-622.

9. Peters BS, Armijo PR, Krause C, Choudhury SA, Oleynikov D. Review of emerging surgical robotic technology. Surgical Endoscopy. 2018;32(4):1636-1655.

10. Ullah S, Ali FS, Liu BR. Advancing flexible endoscopy to natural orifice transluminal endoscopic surgery. Curr Opin Gastroenterol. 2021;37(5):470-477.

11. Kaymakçı Ş. Ameliyathane hemşireliği görev yetki ve sorumlulukları. In: Yavuz van Giersbergen M, Kaymakçı Ş, eds. Ameliyathane Hemşireliği. İzmir: Meta Basım Matbaacılık; 2015:1-18.

12. Markatos K, Karamanou M, Saranteas T, Mavrogenis AF. Hallmarks of amputation surgery. Int Orthop. 2019;43(2):493-499.

13. Collado-Vázquez S, Carrillo JM. Cranial trepanation in The Egyptian. Neurologia. 2014;29(7):433-40.

14. Kuo Tai Fu L. The origins of surgery: 1. From prehistory to Renaissance. Ann. Coll. Surg. 1999;4:127-136. 
15. Zargaran A, Fazelzadeh A, Mohagheghzadeh A. Surgeons and surgery from ancient Persia (5,000 years of surgical history). World Journal of Surgery. 2013;37(8):2002-4.

16. Mitchell PD. Anatomy and surgery in Europe and the Middle East during the Middle Ages. https://core.ac.uk/download/pdf/96707273.pdf. Erişim tarihi 20 Ağustos 2019.

17. Dobanovački D, Milovanović L, Slavković A, et al. Surgery before common era (B.C.E.*). Arch Oncol. 2012;20(1-2):28-35.

18. Şentürk SE. İlk çağlarda hasta bakımı tarihçesi. In: Şentürk SE. ed. Hemşirelik Tarihi. İstanbul: Nobel Tıp Kitabevi;2011:1-24.

19. Debakey ME. A surgical perspective. Ann Surg. 1991;213(6):499-531.

20. Eti Aslan F. Cerrahi hemşireliğinin tarihçesi. Atatürk Üniversitesi Hemşirelik Yüksekokulu Dergisi. 2009;12(1):104-113.

21. Pouyan N. Mesopotamia, the cradle of civilization and medicine. World Journal of Pharmaceutical Research. 2016;5(4):192-225.

22. Banerjee AD, Ezer H, Nanda A. Susruta and ancient Indian neurosurgery. World Neurosurg. 2011;75(2):320-3.

23. Tubbs RS, Riech S, Verma K, Chern J, Mortazavi M, Cohen Gadol AA. China's first surgeon: Hua Tuo (c. 108-208 AD). Childs Nerv Syst. 2011;27(9):1357-60.

24. Ökdem Ş, Abbasoğlu A, Doğan N. Hemşirelik Tarihi, Eğitimi ve Gelişimi. Ankara Sağhk Hizmetleri Dergisi. 2000;1(1):1-5.

25. Beg H. Surgical principles of Ibni Sina (Avicenna). Bangladesh Journal of Medical Science. 2015;14(3):217-220.

26. Edriss H, Rosales BN, Nugent C, Conrad C, Nugent K. Islamic medicine in the middle ages. Am J Med Sci. 2017;354(3):223-229.

27. Al-Benna S. Albucasis, a tenth-century scholar, physician and surgeon: His role in the history of plastic and reconstructive surgery. European Journal of Plastic Surgery. 2012;35(5):379-387.

28. Bilgin TE. Anestezide öncüler ve keşifler tarihi. Lokman Hekim Journal. 2013;3(2):37-52.

29. Langer RM. Vladimir P. Demikhov, a pioneer of organ transplantation. Transplantation Proceedings. 2011;43(4):1221-1222.

30. Runciman M, Darzi A, Mylonas GP. Soft robotics in minimally invasive surgery. Soft Robot. 2019;6(4):423-443.

31. Diana M, Marescaux J. Robotic surgery. Br J Surg. 2015;102(2):e15-28.

32. Schwartz C. What is minimally invasive surgery? Eur J Orthop Surg Traumatol. 2018;28(5):759-760.

33. Huda NM, Yu H, Cang S. Robots for minimally invasive diagnosis and intervention. Robotics and Computer-Integrated Manufacturing. 2016;41:127-144.

34. Camarillo DB, Krummel TM, Salisbury JK. Jr. Robotic technology in surgery: Past, present, and future. American Journal of Surgery. 2004;188(4):2-15.

35. Ghezzi TL, Corleta OC. 30 years of robotic surgery. World Journal of Surgery. 
2016;40(10):2550-2557.

36. Vercelli A, Rainero I, Ciferri L, Boido M, Pirri F. Robots in elderly care. Scientific Journal on Digital Cultures. 2017; 2(2):37-50.

37. Koh DH, Jang WS, Park JW, et al. Efficacy and safety of robotic procedures performed using the da vinci robotic surgical system at a single institute in Korea: Experience with 10000 cases. Yonsei Med J. 2018;59(8):975-981.

38. Zureikat AH, Moser AJ, Boone BA, Bartlett DL, Zenati M, Zeh 3rd HJ. 250 robotic pancreatic resections: safety and feasibility. Ann Surg. 2013;258(4):554-9;559-62.

39. Avcı C, Avtan L, Özmen MM. Teletıp ve robotik cerrahi. Bilim ve Teknik. 2007;1-14. http://www.bilimteknik.tubitak.gov.tr/content/robotik-cerrahi Erişim tarihi 20 Ağustos 2019.

40. Pandya A, Eslamian S, Ying H, Nokleby M, Reisner LA. A Robotic recording and playback platform for training surgeons and learning autonomous behaviors using the da vinci surgical system. Robotics. 2019;8(1):1-9.

41. Hussain A, Malik A, Halim MU, Ali AM. The use of robotics in surgery: A review. Int $J$ Clin Pract. 2014;68(11):1376-82.

42. Nakazawa A, Nanri K, Harada K, et al. Feedback Methods for collision avoidance using virtual fixtures for robotic neurosurgery in deep and narrow spaces. 6th IEEE RAS/EMBS International Conference on Biomedical Robotics and Biomechatronics. 2016;247-252.

43. Clancy TR. Artificial intelligence and nursing: the future is now. JONA. 2020;50(3):125127.

44. McGrow K. Artificial intelligence essentials for nursing. Nursing. 2019; 49(9):46-49.

45. Robert N. How artificial intelligence is changing nursing. Nurs Manage. 2019;50(9):30-39.

46. Erdağı Oral S. Cerrahi Hemşireliği. In: Çelik S, ed. Cerrahi Hemşireliğinde Güncel Uygulamalar. Ankara: Çukurova Nobel Tıp Kitabevi;2021:1-16.

47. Velioğlu P. Hemşirelikte Kavram ve Kuramlar.1. baskı. İstanbul: Akademi Basın ve Yayıncillk; 2012.

48. Hamlin L. From theatre to perioperative: A brief history of early surgical nursing. Journal of Perioperative Nursing. 2020;33(4):e-19-e-24.

49. Yılmaz Gören Ş, Yasemin Yalım N. Hemşirelik Tarihinde Bir Öncü “Safiye Hüseyin Elbi”. Lokman Hekim Dergisi. 2016;6(2):38-45.

50. Karadağ M. Cerrahi hemşireliği. In: Karadağ M, Bulut H. eds. Kavram Haritası ve Akış Şemah Cerrahi Hemşireliği. Ankara: Vize Basın Yayın; 2019:451-464. 